\title{
Ocorrência de anticorpos anti-Brucella ovis em ovinos com histórico de distúrbios reprodutivos no estado de São Paulo, Brasil
}

\author{
Occurrence of antibodies anti-Brucella ovis in ovine with history of \\ reproductive disorders in São Paulo, Brazil
}

\author{
Huber Rizzo ${ }^{1 *}$, Lilian Gregory², Fidel Beraldi ${ }^{3}$, Aline Feola de Carvalho ${ }^{4}$, Eliana Scarcelli Pinheiro ${ }^{4}$, \\ Lília Márcia Paulin ${ }^{4}$
}

| | | | | | | | | | | | | | | | | | | | | | | | | | | | | | | | | | | | | | | | | | | | | | | | | | | | | | | | | | | | | | | | | | | | | | | | | | | | | | | | | | | | | | | | | | | | | | | | | | | | | | | | | | | | | | | | | | | | | | | | | | | | | | | | | | | | | | | | | | | | | | | | | | | | | | | | | | | | | | | | | | | | | | | | | | | | | | | | | | | | | | | | | | | | | |

\begin{abstract}
RESUMO: Com base no histórico de distúrbios reprodutivos, foram realizados inquéritos sorológicos e tentativas de isolamento de Brucella ovis em 28 propriedades do estado de São Paulo, totalizando 294 ovinos. Os soros colhidos por ocasiáo das visitas aos estabelecimentos rurais foram submetidos ao teste de fixação do complemento. Durante os exames clínicos, também foram colhidas amostras de materiais biológicos suspeitos para posterior cultivo bacteriológico em meio Brucella ágar, num total de 16 fetos abortados, um útero, seis secundinas, 13 secreçôes uterinas, seis zaragatoas de muco vaginal, 17 amostras de sêmen e três zaragatoas prepuciais. A proporção de ovinos com histórico de distúrbios reprodutivos e sororreativos para $B$. ovis foi de $1,7 \%$ (5/294), sendo um macho e quatro fêmeas, com títulos variando de 800 UI a 1.600 UI. Quatro rebanhos dos 28 pesquisados apresentaram animais sororreagentes (14,3\%). Todos os cultivos das amostras biológicas foram negativos, inclusive sêmen e órgáos reprodutivos de carneiro da raça Texel, positivo em dois testes de fixação de complemento com intervalo de seis meses. Nos rebanhos de ovinos do estado de São Paulo examinados, não foi possível relacionar os distúrbios reprodutivos à sorologia positiva para B. ovis. No entanto, foi detectada presença de focos, fator de risco para a disseminação da bactéria nos rebanhos.
\end{abstract}

PALAVRAS-CHAVE: aborto; brucelose; ovino.

\begin{abstract}
Based upon a history of reproductive disorders, a serological survey and attempts to isolate Brucella ovis were performed in 28 farms in the State of São Paulo, in a total of 294 sheep. The sera sampled on the occasion of the visit to the farms were subject to complement fixation. During clinical examination, samples of several suspicious biological materials were collected for further bacterial culture in Brucella agar medium, in a total of 16 aborted foetuses, one uterus, one placenta, 13 uterine discharge, six vaginal swabs, 17 semen samples and three preputial swabs. The proportion of sheep with a history of reproductive disorders and serum reactive for $B$. ovis was of $1.7 \%(5 / 294)$, including one ram and four ewes, with titres ranging from 800 IU to 1600 IU. Four of the 28 sheep herds surveyed had serum reactive animals (14,3\%). All cultures of biological samples were negative, including semen and swabs from the reproductive organs of a Texel ram, positive in two complement fixation tests, six months apart. In the sheep herds surveyed in the State of São Paulo, it was not possible to relate the reproductive disorders to the positive serology for B. ovis, however, foci were detected, representing a risk factor for bacterial dissemination in the herds.
\end{abstract}

KEYWORDS: abortion; brucellosis; sheep.

'Departamento de Medicina Veterinária; Universidade Federal Rural de Pernambuco (UFRPE) - Recife (PE), Brasil.

${ }^{2}$ Departamento de Clínica Médica da Faculdade de Medicina Veterinária e Zootecnia; Universidade de São Paulo (USP) - São Paulo (SP), Brasil.

${ }^{3}$ Instituto de Matemática e Estatística (USP) - São Paulo (SP), Brasil.

${ }^{4}$ Laboratório de Doenças Bacterianas da Reprodução do Centro de Pesquisa e Desenvolvimento de Sanidade Animal; Instituto Biológico - São Paulo (SP), Brasil.

*Autor correspondente: hubervet@gmail.com

Recebido em: 24/10/2012. Aceito em: 20/12/2013 


\section{INTRODUÇÃO}

A brucelose ovina é uma doença infecciosa crônica causada pela Brucella ovis, acometendo o trato reprodutivo com quadros de orquite, epididimite, placentite, abortamentos e morte de cordeiros (Homse et al., 1999; NAREZ et al., 1999). No Brasil, o primeiro diagnóstico clínico de brucelose por B. ovis foi firmado por Ramos et al. (1966) no Rio Grande do Sul, na identificação de 220 carneiros com epididimite clínica associada ao isolamento de um agente comum, não citado no trabalho. No mesmo Estado, posteriormente, foi relatado o isolamento de bactérias semelhantes à Brucella de epidídimo de carneiros com epididimite clínica, e conteúdo estomacal de cordeiros natimortos (Boblel et al., 1972).

Em São Paulo, Marinho; Mathias (1996) não encontraram ovinos soropositivos a $B$. ovis nos testes de imunodifusão de ágar gel (IDGA), teste imunoenzimático indireto (ELISA-I) e reação de fixação do complemento (FC-O), bem como não observaram alteraçôes sugestivas de infecção pela bactéria ao exame clínico dos 850 ovinos, assim como Chiebao (2011), utilizando a IDGA em 180 ovinos sem sintomatologia do município de Piedade. Nozaki et al. (2004) e Ueno (2010), utilizando IDGA como teste de triagem e IDGA acrescido de 2-mercaptoetanol (IDGA com 2-ME), como prova confirmatória, obtiveram $1,7 \%$ e $12 \%$ de ovinos soropositivos na IDGA sem 2 -ME, e $0,26 \%$ e $1,1 \%$ no teste confirmatório em 1.529 e 1.033 amostras, respectivamente. MagalHâes; Gil-Tunes (1996), no Rio Grande do Sul, de 1.638 carneiros encontraram anticorpos anti-Brucella ovis em 13,4\% e, no Paraná, têm sido relatadas baixas ocorrências, de $0,9 \%(1 / 109)$ e $1,4 \%$ (3/213) (Reis, 2005; Cunha Filho et al., 2007). Em Santa Catarina, em 69 carneiros, sendo 18,84\% com alteraçóes nos órgãos genitais, e em Uberlândia $(\mathrm{n}=344)$ não foram observadas reaçóes positivas na IDGA para B. ovis (SCHAFER et al., 1997; SALABerry et al., 2011).

No nordeste brasileiro, os levantamentos sorológicos apresentaram variaçôes de $0,72 \%$ a $35 \%$. Estudos realizados em três regiōes da Bahia apresentaram baixa ocorrência e resultados variáveis, de 3,27\% (6/183), 0,72\% (5/697) e 6,94\% (55/793), respectivamente, no Recôncavo Baiano e microrregiôes de Juazeiro e Feira de Santana (Silva et al., 2009; Souza et al., 2012; Araújo et al., 2013). Em Alagoas, a ocorrência foi de $3,1 \%$, principalmente em fêmeas maiores de 24 meses de idade, oriundas de criaçóes extensivas e que apresentavam transtornos reprodutivos (Pinheiro Junior et al., 2009). Em Pernambuco, Coleto et al. (2003) encontraram 16,25\% de ovinos de ambos os sexos soropositivos na IDGA, e Pinheiro Junior et al. (2003) encontraram 9,09\% (19/209) de positivos e 1,91\% (4/209) de reaçôes fracas pelo mesmo teste. $\mathrm{Na}$ Paraíba, dos três levantamentos realizados nos últimos anos, a maior ocorrência foi obtida por Alves et al. (2010), com 7,5\% (6/80) de soropositivos entre ovinos abatidos no abatedouro municipal de Patos (PB), além da detecçâo de $B$. ovis em pool de testículos e epidídimos pela reaçáo em cadeia de polimerase (PCR). Os demais levantamentos no Estado, realizados em rebanhos comerciais, apresentaram resultados semelhantes, de 5,57\% (28/498) e 5,9 \% (59/1134) (Clementino et al., 2007; SAntos et al., 2013). Silva et al. (2003) e Azevedo et al. (2004) obtiveram 35\% (103/290) e 11,3\% (13/115) de soropositivos, respectivamente, no Rio Grande do Norte, e BATISTA et al. (2001) obtiveram 7,81\% (30/383) no Ceará. Na regiáo Norte, no município de Colinas (TO), das 142 amostras analisadas, $31,6 \%$ reagiram ao teste de IDGA; dentre estas, apenas quatro $(2,8 \%)$ foram confirmadas na fixação de complemento (MARTins et al., 2013).

Ao atingirem a fase reprodutiva, os ovinos estâo mais expostos à infecçáo por B. ovis, (Martins et al., 2013) através da ingestão e/ou contato sexual com descargas genitais, do coito, principalmente durante a estação de monta (QuisPE et al., 2002), da atividade homossexual de carneiros (Robles, 1998) e do contato com fetos abortados, secundinas e/ou fômites e pastagens contaminadas (Ocholi et al., 2004). A B. ovis pode ainda contaminar embriōes, na inseminação artificial com sêmen contaminado, aderindo à zona pelúcida (Wolfe et al., 1988).

Estudos nacionais e internacionais apontam falhas de manejo como fatores de risco de introdução e manutenção de focos de B. ovis nos rebanhos. Dentre os relatados estáo a falta de higiene nas instalações, ou sua realização semestral ou anual, a inadequada remoção e destinação de fezes, que contaminam bebedouros e comedouros, a introdução de ovinos de rebanhos náo-livres de brucelose ou de estado sanitário desconhecido, a participação em feiras e exposiçóes agropecuárias e o contato entre diferentes rebanhos em pastagens comuns. Em contrapartida, a desinfecçáo de instalaçôes mais de três vezes ao ano com o uso de desinfetantes, o fornecimento de água encanada e a disponibilidade de serviço veterinário na propriedade diminuem o risco da infecçáo (Mainar; VázQuez-Bolande, 1999; Reviriego et al., 2000; Al-Talafhah et al., 2003; Clementino et al., 2007; Coelho et al., 2007; AL-Majali et al., 2007; SANtos et al., 2013).

Os sinais clínicos iniciais da infecção de ovinos por $B$. ovis são: febre, inapetência, dispneia, orquite e epididimite, e os principais órgãos acometidos são os epidídimos, túnica vaginal, testículos e placenta (Buddle, 1956; Robles, 1998). Geralmente, em casos de orquite/epididimite por B. ovis, observa-se histologicamente a presença de granulomas nas três porçóes do epidídimo, cistos epiteliais, infiltrados de células mononucleares e esclerose de vasos (NAREZ et al., 1999). A presença de leucócitos no sêmen é um indicativo de infecção clínica causada por B. ovis, podendo ser utilizada como técnica de triagem e auxílio ao diagnóstico (KimberLing et al., 1986), uma vez que carneiros infectados com epididimite podem excretar o micro-organismo no sêmen ou apenas apresentarem resposta sorológica sem a presença de sinais clínicos no trato reprodutivo (QUISPE et al., 2002). 
O diagnóstico da brucelose ovina envolve histórico do rebanho, exame clínico, isolamento bacteriano, PCR e provas sorológicas, como a fixaçâo de complemento, teste de imunodifusão em ágar gel e teste de ELISA indireto (MagalHães; Gil-Tunes, 1996; Ficapal et al., 1998; Alves et al., 2010; Greve et al., 2011; Martins et al., 2013). Estudo realizado com ovinos na Nova Zelândia em condiçốes experimentais demonstraram, para as provas de fixaçáo de complemento, imunodifusão em ágar gel e ELISA indireto, sensibilidades de $96,3 \%, 91,7 \%$ e $97,2 \%$, e especificidade de $99,3 \%, 100 \%$ e $98,6 \%$, respectivamente (Worthington et al., 1984). Ficapal et al. (1998) estudaram a relaçáo entre o diagnóstico sorológico, bacteriano e clínico em 110 ovinos e observaram: $50,9 \%$ de animais sororreagentes, $30,9 \%$ sororreagentes e com lesóes testiculares macroscópicas, $20,9 \%$ soronegativos e com lesôes testiculares macroscópicas e $23,6 \%$ de isolamentos bacterianos, concluindo que grande parte dos animais sororreagentes não excreta a bactéria no sêmen.

Objetivou-se neste estudo verificar a ocorrência de anticorpos anti-Brucella ovis em ovinos do estado de Sáo Paulo que apresentaram distúrbios reprodutivos em passado recente, assim como associá-los à presença da bactéria e aos sinais clínicos observados no trato reprodutivo após exame ginecológico e andrológico.

\section{MATERIAL E MÉTODOS}

Foram colhidas amostras de sangue para obtenção de soro de 294 ovinos adultos com histórico de distúrbios reprodutivos, observados pelos proprietários, nos últimos seis meses, sendo 257 fêmeas e 37 machos, de 28 propriedades do estado de São Paulo pertencentes aos municípios de Atibaia, Campinas, Cunha, Indaiatuba, Itapevi, Itatiba, Itu, Itupeva, Jundiaí, Morungaba, Pedra Bela, Piedade, Piracaia, Pirassununga, Santa Rita do Passa Quatro, Santo Anastácio, São Paulo, Sorocaba, Valinhos e Vargem, durante os anos de 2008 e 2009 (Tabela 1). Os municípios contemplados foram escolhidos em função do conhecimento prévio de proprietários que concordaram com a realizaçáo da investigaçáo, sendo que dentro dos rebanhos a amostragem foi de conveniência, já que foram obtidas exclusivamente amostras das matrizes e reprodutores que apresentaram histórico de distúrbios reprodutivos, havendo, por isso, variação do número de amostras coletadas em cada propriedade, de 1 a 40 .

Foram utilizados ovinos de rebanhos das raças Santa Inês $(\mathrm{n}=157)$, Texel $(\mathrm{n}=48)$, Ille de France $(\mathrm{n}=33)$, Dorper $(\mathrm{n}=29)$, Sulfok $(\mathrm{n}=5)$, Laucane $(\mathrm{n}=2)$ e mestiços, resultado de cruzamentos entre elas $(n=20)$, que pertenciam a propriedades apresentando características de sistema de criação

Tabela 1. Ocorrência de ovinos sororeagentes à $B$. ovis na fixação de complemento, segundo a procedência dos animais e sexo e amostras coletadas para pesquisa de $B$. ovis pela técnica de isolamento bacteriano segundo suas procedências no estado de São Paulo.

\begin{tabular}{|c|c|c|c|c|}
\hline \multirow{2}{*}{ Municípios } & \multirow{2}{*}{ Propriedades } & \multicolumn{2}{|c|}{ Amostras de Soro } & \multirow{2}{*}{ Amostras submetidas ao isolamento bacteriano } \\
\hline & & Fêmeas & Machos & \\
\hline Atibaia & $0 / 3$ & 0/19 & - & Feto (2) e secreção uterina ( 1 ) \\
\hline Campinas & $0 / 1$ & $0 / 3$ & $0 / 4$ & Feto (2) e secreção uterina (2) \\
\hline Cunha & $0 / 1$ & $0 / 7$ & - & - \\
\hline Indaiatuba & $0 / 1$ & $0 / 11$ & $0 / 6$ & Muco vaginal (2), secreção uterina (1) e sêmen (6) \\
\hline Itapevi & $0 / 1$ & $0 / 10$ & - & Feto (3), secreção uterina (1) e secundinas (3) \\
\hline Itatinga & $1 / 1(100 \%)$ & $2 / 44$ & $0 / 1$ & Feto (1), secreção uterina (4) e secundinas (2) \\
\hline Itu & $0 / 2$ & $0 / 3$ & $0 / 1$ & - \\
\hline Itupeva & $0 / 1$ & $0 / 30$ & $0 / 1$ & Feto (1) e zaragatoa prepucial (1) \\
\hline Jundiaí & $1 / 3(33,3 \%)$ & $1 / 45(2,22 \%)$ & $0 / 1$ & $\begin{array}{c}\text { Feto ( } 1 \text { ), muco vaginal ( } 2 \text { ), secundinas ( } 1 \text { ), secreção } \\
\text { uterina ( } 3 \text { ) e sêmen ( } 1 \text { ) }\end{array}$ \\
\hline Morungaba & $0 / 2$ & $0 / 6$ & $0 / 2$ & $\begin{array}{l}\text { Muco vaginal ( } 1 \text { ), secreção uterina ( } 1 \text { ), sêmen (1) e } \\
\text { zaragatoas prepuciais (1) }\end{array}$ \\
\hline Pedra Bela & $1 / 3(33,3 \%)$ & $1 / 46(2,17 \%)$ & $1 / 17(5,9 \%)$ & $\begin{array}{l}\text { Muco vaginal ( } 1 \text { ), secreção uterina (2), sêmen (6), zaragatoa } \\
\text { prepucial ( } 1 \text { ), órgãos e fluidos (útero, fígado, baço, rim, } \\
\text { bexiga, pênis, epidídimos, próstata, urina e bile) }\end{array}$ \\
\hline Piedade & $0 / 1$ & $0 / 5$ & - & - \\
\hline Piracaia & $0 / 1$ & $0 / 4$ & $0 / 1$ & Sêmen (1) \\
\hline Pirassununga & $0 / 1$ & $0 / 1$ & - & - \\
\hline $\begin{array}{l}\text { Santa Rita do } \\
\text { Passa Quatro }\end{array}$ & $0 / 1$ & $0 / 1$ & - & - \\
\hline Santo Anastácio & $0 / 1$ & $0 / 14$ & $0 / 1$ & - \\
\hline São Paulo & $0 / 1$ & $0 / 1$ & - & - \\
\hline Valinhos & $0 / 1$ & $0 / 1$ & $0 / 1$ & Sêmen (1) \\
\hline Vargem & $1 / 2(50 \%)$ & $1 / 6(16,7 \%)$ & $0 / 1$ & Sêmen (1) \\
\hline Total & $4 / 28(14,3 \%)$ & $4 / 257(1,56 \%)$ & $1 / 37(2,7 \%)$ & 35 amostras \\
\hline
\end{tabular}


intensiva $(n=80)$ e semiextensiva $(n=214)$, em sua maioria com a finalidade de produção de matrizes e reprodutores. Dezesseis $(57,1 \%)$ delas eram responsáveis por $55,1 \%$ dos ovinos do estudo, com aplicaçáo de alguma biotecnologia da reproduçấo, além da monta natural no manejo reprodutivo.

As fêmeas foram submetidas ao exame clínico geral e ginecológico através da passagem de espéculo auxiliado por fonte de luz para a inspeçấo da vagina e entrada da cérvix, assim como pesquisa de alteraçôes clínicas evidentes, como: coloração de mucosa, cistos, eritemas, nódulos, petéquias, pústulas, telangectasia, vesículas, traumas, presença de secreçôes ou outras relacionadas a casos de vulvovaginete, vaginocervicite e endometrite (Rosenberger, 1993). O histórico de distúrbios reprodutivos em passado recente foi pesquisado junto aos proprietários com o intuito de localizar animais que tivessem apresentado, nos últimos seis meses, quadros que pudessem comprometer a taxa de prenhes e concepçáo dos rebanhos, como: repetição de cio, abortamentos, nascimento de cordeiros "fracos" ou natimortos, parto distócico, retenção de secundina, endometrite, orquite, epididimite e hipoplasia testicular. Dentre os carneiros, 23 não apresentaram distúrbios reprodutivos, no entanto, participaram do estudo pelo contato direto com fêmeas que os possuíam.

A pesquisa de anticorpos anti-Brucella ovis foi realizada por meio do teste de fixação do complemento para B. ovis (FC-O), utilizando-se microtécnica descrita pela Organização Internacional de Epizootias (OIE), executada em placas de poliestireno com fundo em "U", com incubação à temperatura de $37^{\circ} \mathrm{C}$ durante 30 minutos, em estufa bacteriológica, nas duas fases da reaçáo e ponto de corte de 50 . Foram empregados $25 \mu \mathrm{L}$ de cada componente: soro teste, antígeno, complemento e sistema hemolítico. O antígeno utilizado foi o B. ovis amostra REO 198, produzido pelo Instituto de Tecnologia do Paraná (TECPAR), na diluição de 1:50, padronizado por comparaçáo com o soro padráo internacional de referência anti-Brucella ovis adquirido no Central Veterinary Laboratory. Inicialmente, os soros foram diluídos de 1:5 em tampão Veronal (VB). Em seguida, as placas foram deixadas em banho-maria a $60^{\circ} \mathrm{C}$, durante 60 minutos, para inativar o complemento.

Os materiais coletados para tentativa de isolamento bacteriano e seus municípios de origem estấo dispostos na Tabela 1. De um macho sororreagente a $B$. ovis foram colhidas amostras de órgãos e fluidos após a eutanásia, realizada com administraçáo de tiopental sódico $(90 \mathrm{mg} / \mathrm{kg} / \mathrm{IV})$ seguida de KCL ( $50 \mathrm{~mL} / \mathrm{IV})$. Todas as amostras foram acondicionadas em frascos plásticos estéreis e refrigeradas até o momento do diagnóstico, realizado até 24 horas após a colheita. O procedimento bacteriológico para isolamento de Brucella spp. em amostras de sêmen in natura de secreçôes e mucos genitais foi realizado segundo Hotr et al. (1994). As colônias foram identificadas por meio da coloraçáo de Gram e submetidas à série bioquímica correspondente ao agente suspeito, segundo o Bergey's Manual of Determinative Bacteriology. Amostras de conteúdo gástrico e fragmentos de órgãos fetais (rim, figado, pulmão e baço) foram submetidos ao processamento bacteriológico, segundo SCARCELLI et al. (2004).

$\mathrm{Na}$ análise estatística foram utilizadas técnicas descritivas multidimensionais para avaliar a proporção e a quantidade de indivíduos em cada grupo das variáveis, e na comparação entre os grupos, técnicas de análise de dados categorizados forneceram valores de p para aceitar ou rejeitar a associaçấo entre os grupos. Os testes dos grupos que apresentaram associações significantes $(\mathrm{p}<0,1)$ foram avaliados sob a ótica da regressão logística, já que este método estatístico expressa as medidas de riscos entre as variáveis do modelo. No desenvolvimento das análises estatísticas foram utilizados os softwares R.2.7.1 (www.r-project.org), Minitab 14 e SPSS versão 15 (Paulino; Singer, 2006).

Este trabalho foi realizado conforme os princípios éticos da experimentação animal estabelecidos pela Universidade de São Paulo, conforme consta em declaração emitida pela Comissão de Bioética da Faculdade de Medicina Veterinária e Zootecnia, em 18/07/2007.

\section{RESULTADOS}

A frequência de ovinos com histórico de distúrbios reprodutivos sororreagentes a B. ovis foi de 1,7\% (5/294), sendo quatro fêmeas e um reprodutor que apresentaram dois resultados positivos pelo FC-O em intervalo de seis meses. Os ovinos pertenciam a quatro rebanhos diferentes, acometendo 14,3\% (4/28) das propriedades (Tabela 1). As titulações das amostras reagentes foram de 800 U.I. em três fêmeas (duas da raça Santa Inês e uma Sulfock), e as outras duas com titulação de 1.600 U.I. (uma fêmea da raça Santa Inês e um macho Texel) (Tabelas 2 e 3). Das ovelhas soropositivas, três possuíam histórico de abortamento e uma de repetição de cio (Tabela 2), enquanto o macho não apresentava alteraçôes clínicas à inspeção e à palpação do trato reprodutivo (Tabela 3). Em nenhum caso entre as 26 fêmeas e 15 machos pesquisados que pertenciam ao rebanho do reprodutor foram observados anticorpos anti-Brucela ovis.

Em relação ao sexo, raça, sistema de criação e manejo reprodutivo da propriedade, ambos mostraram-se igualmente expostos à infecção por $B$. ovis $(\mathrm{p}=0,62, \mathrm{p}=0,85, \mathrm{p}=0,52$, $\mathrm{p}=0,83$, respectivamente). Náo foi possível associar ovinos sororeagentes a $B$. ovis com os sinais clínicos observados durante exame ginecológico e andrológico, assim como com episódios de distúrbios reprodutivos relatados pelos proprietários $(\mathrm{p}<0,1)$ (Tabelas 2 e 3).

Não ocorreu isolamento bacteriológico de $B$. ovis em nenhuma das amostras biológicas colhidas, e tampouco foram observadas alteraçôes macroscópicas no trato reprodutivo do macho necropsiado. 


\section{DISCUSSÃO}

Neste estudo, a presença de ovinos que apresentaram casos de distúrbios reprodutivos não refletiu na alta ocorrência de animais soropositivos, diferentemente dos dados de PinHeIro Junior et al. (2009), em Alagoas, que observaram maior ocorrência de soropositivos em rebanhos com distúrbios reprodutivos. O risco de infecção entre fêmeas e machos apresentou-se o mesmo, assim como observado em outras regióes do Brasil (Silva et al., 2003; Clementino et al., 2007; Silva et al., 2009; ARAújo et al., 2013).

A ocorrência de 1,7\% de ovinos soropositivos manteve-se abaixo de outros trabalhos nacionais, principalmente os realizados na regiáo Nordeste, que possui características de criaçōes extensivas, menor tecnificação e contato maior entre os rebanhos devido ao hábito de compartilhar reprodutores e pastagens (Magalháes; Gil-Tunes, 1996; Coleto et al., 2003; Silva et al., 2003; AzEVEDo et al., 2004; NozAKI et al., 2004; Clementino et al., 2007; Pinheiro Junior et al., 2009; Alves et al., 2010), enquanto os ovinos utilizados neste estudo pertenciam a sistemas semi-intensivos ou intensivos, principalmente para a produçáo de matrizes e reprodutores, com maior tecnificação, controle sanitário e capacidade de identificação de animais com alterações clínicas.

Este fato foi observado também por Clementino $e t$ al. (2007), que não encontraram animais soropositivos em propriedades da Paraíba com finalidade de criaçáo de animais para reprodução, enquanto nas de subsistência e cria/ recria/engorda observaram $10,3 \%$ e $12,2 \%$ de soropositivos, respectivamente, e entre criadores que participavam ou não de exposições, $10 \%$ e $9,8 \%$, respectivamente. Isso nos alerta quanto ao risco do trânsito de animais para exposiçóes e feiras agropecuárias, assim como observado por SANTOS et al. (2013), uma vez que os cinco ovinos soropositivos do estudo eram oriundos de propriedades que participavam desses eventos, nos quais se exige apenas laudo de ausência de sinais clínicos compatíveis com brucelose ovina. Isso é ineficiente para a identificaçáo dos animais infectados (FICAPAL et al., 1998), fazendo-se necessária a adoção do teste sorológico para maior segurança sanitária nesses eventos. Resultados discordantes dos trabalhos anteriores foram relatados no Rio Grande do Sul, onde se observou maior soropositividade em ovinos mantidos em regime de cabana (MagalHães; GIL-Tunes, 1996) na microrregião de Juazeiro (BA) em exploraçóes predominantemente extensivas, compostas por ovinos localmente adaptados, mestiços e sem raça definida para a produçáo de carne e pele, com baixa produtividade e tecnificação; em Colinas (TO), obteve baixa ocorrência $(2,8 \%)$ em estudo no qual $92,9 \%$ das propriedades adotavam o sistema extensivo de criação.

Nos estudos com rebanhos do estado de Sáo Paulo ou regiôes próximas, como o Norte do Paraná, foram observadas

Tabela 2. Histórico de distúrbio reprodutivo e sororeação para B. ovis pela FC-O em 257 ovelhas do estado de São Paulo.

\begin{tabular}{|c|c|c|c|c|}
\hline \multirow{2}{*}{ Distúrbio Reprodutivo } & \multirow{2}{*}{ Sororreagentes / Total } & \multicolumn{2}{|c|}{ Titulação } & \multirow{2}{*}{ Valor $\mathrm{p}$} \\
\hline & & $800 \mathrm{UI}$ & $1600 \mathrm{UI}$ & \\
\hline Abortamento & $3 / 136$ (2,2\% de 52,9\%) & 2 & 1 & 0,39 \\
\hline Endometrite & $0 / 6(2,3 \%)$ & - & - & - \\
\hline Malformação fetal & $0 / 3(1,2 \%)$ & - & - & - \\
\hline Morte neonatal & $0 / 34(13,2 \%)$ & - & - & - \\
\hline Nascimento de cordeiro fraco & $0 / 30(11,7 \%)$ & - & - & - \\
\hline Natimortalidade & $0 / 7(2,7 \%)$ & - & - & - \\
\hline Parto distócico & $0 / 6(2,3 \%)$ & - & - & - \\
\hline Parto prematuro & $0 / 3(1,2 \%)$ & - & - & - \\
\hline Prolapso uterino & $0 / 2(0,8 \%)$ & - & - & - \\
\hline Repetição de cio & $1 / 77$ ( $1,3 \%$ de $30 \%)$ & 1 & - & 0,83 \\
\hline Retenção de secundinas & $0 / 3(1,2 \%)$ & - & - & - \\
\hline Total & $4 / 257(1,56 \%)$ & $3 / 4(75 \%)$ & $1 / 4(25 \%)$ & \\
\hline
\end{tabular}

Tabela 3. Histórico de distúrbio reprodutivo e sororreação para B. ovis pela FC-O em 37 carneiros do estado de São Paulo.

\begin{tabular}{|c|c|c|c|}
\hline \multirow{2}{*}{ Distúrbio Reprodutivo } & \multirow{2}{*}{ Sororreagentes / Total } & \multicolumn{2}{|c|}{ Titulação } \\
\hline & & $800 \mathrm{UI}$ & $1600 \mathrm{UI}$ \\
\hline Baixa fertilidade & $0 / 5(13,5 \%)$ & - & \\
\hline Controle & $1 / 23(4,3 \%$ de $62,3 \%)$ & - & 1 \\
\hline Degeneração testicular & $0 / 2(5,4 \%)$ & - & \\
\hline Falta de libido & $0 / 4(10,8 \%)$ & - & \\
\hline Hiperplasia de epidídimo & $0 / 1(2,7 \%)$ & - & \\
\hline Hiperplasia testicular unilateral & $0 / 2(5,4 \%)$ & - & \\
\hline Total de carneiros & $1 / 37(2,7 \%)$ & - & 1 \\
\hline
\end{tabular}


baixas ocorrências, e até nulas, como o realizado na regiáo de Piedade (SP), com amostras exclusivamente de matrizes e reprodutores (Marinho; Mathias, 1996; Cunha Filho et al., 2007; Ueno, 2010; Chiebao, 2011), confirmando nossos resultados. No entanto, o cuidado com a sanidade deve ser mantido, uma vez que a presença de alguns focos nos rebanhos pode desencadear a disseminação, principalmente em sistemas de cabana, devido à maior concentração em espaços reduzidos (MagalHâes; Gil-Tunes, 1996).

Três das quatro fêmeas soropositivas apresentaram em seu histórico quadro de abortamento, podendo servir como foco de disseminação da bactéria no rebanho, contaminando carneiros no momento do coito (QUISPE et al., 2002), além de eliminar a bactéria no ambiente por meio dos produtos do abortamento, predispondo a infecção oral (BuDdLE, 1956; Marco et al., 1994), uma vez que pertenciam à propriedade que utiliza aprisco, sendo que os animais passavam a noite e recebiam alimentação no cocho. Isso favorece o contato direto entre ovinos e com seus produtos biológicos, que podem carrear a bactéria (Ocholi et al., 2004). Duas fêmeas positivas pertenciam a cabanhas que realizavam colheita e transferência de embrióes, além da monta natural, potencializando a disseminação da bactéria devido à sua capacidade de adesão à zona pelúcida se não forem realizados os procedimento de lavagens de embrióes, que são recomendados pela Sociedade Internacional de Transferência de Embrióes (Wolfe et al., 1988). A conformação da B. ovis como agente etiológico desses casos de aborto, apesar da sorologia positiva, não ocorreu devido à impossibilidade de coleta de fetos e secundinas dessas fêmeas, para a confirmação através do isolamento bacteriano.

Dos 37 machos que foram submetidos ao diagnóstico de $B$. ovis, apenas um foi sororreagente, assim como observado por outros autores (Pinheiro Júnior et al., 2003; Silva et al., 2009; Souza et al., 2012). O reprodutor não apresentava sinais clínicos à inspeção e à palpação de testículos e epidídimos (Burgess et al., 1982; Quispe et al., 2002) e tampouco alteraçóes macroscópicas no trato reprodutivo, após necropsia, como descrito por BuddLE (1956) e Narez et al. (1999), demonstrando que há falha do diagnóstico exclusivamente pela palpação do trato reprodutivo (Ficapal et al., 2009).

Quispe et al. (2002) relataram que o meio mais seguro para detectar a presença da bactéria no rebanho é o exame sorológico, pois parte dos carneiros não manifestam sinais clínicos e podem carrear e eliminar a bactéria muito tempo antes de apresentar lesóes palpáveis nos testículos e epidídimos. Magalhâes Neto; Gil-Turnes (1996), em 160 carneiros soropositivos ao teste de IDGA, identificaram apenas $9,8 \%$ com manifestaçóes clínicas no trato reprodutivo. Há também a possibilidade de carneiros com lesôes palpáveis serem negativos sorologicamente (SCHAFER et al., 1997), assim como dois reprodutores do estudo que apresentaram quadro de orquite e/ou epididimite foram negativos no isolamento seminal e sorologia para B. ovis. Não foi isolado B. ovis em nenhuma amostra de sêmen ou órgáos do reprodutor soropositivo do estudo, como também na maioria dos animais estudados por Blobel et al. (1972), que a isolaram em oito epidídimos de 24 carneiros com epididimite e sêmen necrospérmico ou azoospérmico, contendo leucócitos e bactérias semelhantes a brucelas, demonstrando a dificuldade do isolamento da bactéria.

A baixa ocorrência de B. ovis nos rebanhos paulistas nos indica que outros agentes etiológicos podem estar ocorrendo nos rebanhos, uma vez que foram utilizados somente animais sabidamente com distúrbios reprodutivos. Faz-se necessária a realização de diagnóstico diferencial através do isolamento bacteriano para Actinobacillus seminis, Campylobacter spp., Histophilus somni, Micoplasmas, além de sorologia para alguns vírus, como o da Maedi-Visna, Língua Azul e Herpesvírus ovino tipo 2 (CARvalHo Júnior et al., 2013) e protozoários, como T. gondii e $N$. caninum. Outros fatores não infecciosos merecem atenção no caso de aumento do volume escrotal, como: hidrocele, hematocele, varicocele, neoplasias, hérnias inguinais, inflamação dos envoltórios, criptorquidismo, espermatocele (PASTOR, 2006), que podem ser diagnosticados pela palpaçáo do trato reprodutivo e que não foram observados nos carneiros do estudo.

\section{CONCLUSÃO}

A ocorrência de ovinos com histórico de distúrbios reprodutivos reagentes à prova de fixação de complemento para B. ovis no estado de São Paulo é baixa, e não foi possível associá-la a sinais clínicos do trato reprodutivo. A brucelose encontra-se presente na regiáo em rebanhos de alto valor zootécnico para comercialização de reprodutores e matrizes, potencializando a transmissão da doença além dos limites da propriedade através da participação em feiras e exposiçôes, comercialização de animais e material genético pelas biotecnologias da reproduçáo, sendo necessárias medidas de controle e prevençáo tanto nas propriedades quanto em eventos agropecuários que envolvam a aglomeração de animais, além da manipulação criteriosa por parte dos laboratórios do material genético oriundo deles. 


\section{REFERÊNCIAS}

AL-MAJALI, A.M.; MAJOK, A.A.; AMARIN, N.M.; AL-RAWASHDEH, O.F. Prevalence of, and risk factors for, brucellosis in Awassi sheep in Southern Jordan. Small Ruminant Research, v.73, p.300-303, 2007.

AL-TALAFHAH, A.H.; LAFI, S.Q.; AL-TARAZI, Y. Epidemiology of ovine brucellosis in Awassi sheep in Northern Jordan. Preventive Veterinary Medicine, v.60, p.297-306, 2003.

ALVES, J.C.; FIGUEIREDO, S.M.; AZEVEDO, S.S.; CLEMENTINO, I.J.; KEID, L.B.; VASCONCELLOS, S.A.; BATISTA, C.S.A.; ROCHA, V.C.M.; HIGINO, S.S. Detection of Brucella ovis in ovine from Paraíba State, in the northeast region of Brazil. Brazilian Journal of Microbiology, v.41, p.365-367, 2010.

ARAÚJO, B.R.; COSTA, J.N.; SOUZA, T.S.; LIMA, C.C.V.; LEITE, M.D.X.; COSTA NETO, A.O.; ANUNCIAÇÃO, A.V.M.; ALMEIDA, M.G.A.R.; LIMA, E.B. Seroepidemiology of sheep brucellosis in the microregion of Feira de Santana, BA, Brazil. Brazilian Journal Veterinary Research Animal Science, v.50, n.2, p.129-135, 2013.

AZEVEDO, S.S.; ALVES, C.J.; BATISTA, C.S.A.; CLEMENTINO, I.J.; SANTOS, F.A.; ALVES, F.A.L. Ocorrência de anticorpos antiBrucella ovis em ovinos procedentes de quatro municípios do Estado do Rio Grande do Norte, Brasil. Agropecuária Técnica, v.25, n.2, p.45-50, 2004.

BATISTA, H.M.F.; ANDRIOLI, A.; PINHEIRO, R.R.; ALVES, F.S.F.; SANTIAGO, L.B. Ocorrência de ovinos soropositivos para Brucella ovis nos rebanhos do Estado do Ceará. In: Encontro de Presquisa e Pós-Graduação da Universidade Estadual Vale do Acaraú, 6 , 2011 , Sobral, CE. Resumos. Sobral: $2011.8 f$.

BLOBEL, H.; FERNANDES, J.C.T.; MIES FILHO, A.; RAMOS, A.A.; TREIN, E.J. Estudos sobre a etiologia da epididimite ovina no Rio Grande do Sul. Pesquisa Veterinária Brasileira, v.7, p.1-4, 1972.

BUDDLE, M.B. Studies on Brucella ovis (n.sp.), a cause of genital disease of sheep in New Zealand and Australia. Journal of Hygienic, v.54, n.3, p.351, 1956.

BURGESS, G.W.; MCDONALD, J.W.; NORRIS, M.J. Epidemiological studies on ovine brucellosis in selected ram flocks. Australian Veterinary Journal, v.59, n.2, p.45-47, 1982.

CARVALHO JÚNIOR, C.A.; XAVIER, M.N.; COSTA, L.F.; SILVEIRA, S.S.; SANT'ANNA, F.M.; BORGES, A.M.; GOUVEIA, A.M.G.; SANTOS, R.L. Agentes infecciosos que podem promover infertilidade em machos da espécie ovina. Revista Brasileira de Reprodução Animal, v.34, n.3, p.160-167, 2010.

CHIEBAO, D.P. Epididimite ovina: análise da situação no município de Piedade, São Paulo. Pesquisa \& Tecnologia, v.8, n. 16, 2011.

CLEMENTINO, I.J.; ALVES, C.J.; AZEVEDO, S.S.; PAULIN, L.M.; MEDEIROS, K.A. Inquérito soro-epidemiológico e fatores de risco associados à infecção por Brucella ovis em carneiros deslanados do semi-árido da Paraíba. Pesquisa Veterinária Brasileira, v.27, n.4, 2007.
COELHO, A.M.; COELHO, A.C.; ROBOREDO, M.; RODRIGUEZ, J. A case-control study of risk factors for brucellosis seropositivity in Portuguese small ruminant herds. Preventive Veterinary Medicine, v.82, p.291-301, 2007.

COLETO, Z.F.; PINHEIRO JÚNIOR, J.W.; MOTA, R.A. Ocorrência de infecção por Brucella ovis em ovinos do Estado de Pernambuco e sua participação em distúrbios reprodutivos nesta espécie (estudos preliminares). Revista Brasileira de Reprodução Animal, v.27, n.3, p.551-553, 2003.

CUNHA FILHO, L.F.; LEUZZI JUNIOR, L.A.; SILVA, L.C.; AGOTTANE, J.V.B.; OKANO, W.; STERZA, F.M.A.; ZANIN, R. Ocorrência de ovinos reagentes à prova de imunodifusão em gel ágar, para Brucella ovis, em propriedades da região norte do Paraná. Revista UNOPAR Científica Ciências Biológicas e da Saúde, v.9, n. 1, p.67-70, 2007

FICAPAL, A.; JORDANA, J.; BLASCO, J.M.; MORIYÓN, I. Diagnosis and epidemiology of Brucella ovis infection in rams. Small Ruminant Research, v.29, p.13-19, 1998.

GREVE, I.C.; SILVA, M.C.A.; TRINDADE, S.; SILVA, D.; MASCARENHAS, M.T.; BAHIA, R.C. Utilização de um antígeno comercial para o teste ELISA indireto na detecção de anticorpos contra brucelose ovina. Ciências Agrárias Ambientais, v.9, n.4, p.379-386, 2011.

HOMSE, A.C.; CASARO, A.P.; CAMPERO, C.M. Infertilidad en ovejas por Brucella ovis. Veterinaria Argentina, v.12, n. 114 , p.243-249, 1995.

KIMBERLING, C.V.; ARNOLD, K.S.; SCHWEITER, D.J.; JONES, R.L.; VON BYERN, H.; LUCAS, M. Correlation of the presence of seminal white blood cells and the prevalence of separated spermatozoal heads with subclinical Brucella ovis infection in rams. Journal of the American Veterinary Medical Association, v.189, n. 1, p.73-76, 1986

MAGALHÃES NETO, A.; GIL-TURNES, C. Brucelose ovina no Rio Grande do Sul. Pesquisa Veterinária Brasileira, v.16, n.2/3, p.75$79,1996$.

MAINAR, R.C.; VÁZQUEZ-BOLANDE, J.A. Associations of veterinary services and farmer characteristics with the prevalence of brucellosis and border disease in small ruminants in Spain. Preventive Veterinary Medicine, v.40, p.193-205, 1999.

MARINHO, M.; MATHIAS, L.A. Pesquisa de anticorpos contra Brucella ovis em ovinos do estado de São Paulo. Pesquisa Veterinária Brasileira, v.16, n.2/3, p.45-48, 1996.

MARTINS, N.E.X.; ALMEIDA, J.D.M.; SILVA, M.G.; SOUSA, M.G.; MATHIAS, L.A.; ALMEIDA, K.S. Prevalência de anticorpos antibrucella ovis e anti-brucella abortus em ovinos do município de Colinas, Tocantins, Brasil. Revista de Patologia Tropical, v.42, n.2, p.147-160, 2013. 
NAREZ, G.M.; APARICIO, E.D.; MORALES-ALVAREZ, J.F.; ROMERO, F.A.; GUEMES, F.S. Ovine epididymitis: bacteriological and serological studies. Veterinaria-Mexico, v.30, p.329336, 1999.

NOZAKI, C.N.; MEGID, K.C.; SILVA JUNIOR, F.F.; VELOSO, C.S. Comparação das técnicas de imunodifusão em gel de ágar e ELISA no diagnóstico de brucelose ovina em cabanhas da região CentroOeste do Estado de São Paulo. Arquivo do Instituto Biológico, v.71, n. 1, p.1-5, 2004.

OCHOLI, R.A.; KWAGA, J.K.P.; AJOGI, I.; BALE, J.O.O. Phenotypic characterization of Brucella strains isolated from livestock in Nigeria. Veterinary Microbiology, v. 103, p.47-53, 2004.

PASTOR, L.M.G. Auteraciones testiculares en muruecos: estudio clinico, serologico, microbiologico y anatomopatológico. 2006. 166f. Tese (Doutorado em Patologia Animal) - Faculdade de Veterinaria, Universidade de Zaragoza, Zaragoza, 2006.

PAULINO, C.D.; SINGER, J. Análise de dados categorizados. São Paulo: Edgard Blucher, 2006, 648p.

PINHEIRO JUNIOR, J.W.; COLETO, Z.F.; MOTA, R.A.; GUERRA, M.M.P.; SOUZA, A.F.; SILVA, D.R . Infecção pela Brucella ovis em ovinos criados no agreste e Zona da Mata do Estado de Pernambuco. In: SINCORTE - Simpósio Internacional sobre Caprinos e Ovinos de Corte, 2., 2003, João Pessoa, PB. Resumos. João Pessoa: 2003. Disponível em: <http://ainfo.cnptia.embrapa.br/ digital/bitstream/item/73440/1/RAC-Sincorte2-SP405.pdf >. Acesso em: $18 \mathrm{dez} .2013$.

PINHEIRO JUNIOR, J.W.; OLIVEIRA, A.A.F.; MOTA, R.A.; AGOTTANI, J.V.; JESUS, E.M.; ASSIS, S.T.; OLIVEIRA, C.Z. Ocorrência de ovinos sororeatores para Brucella ovis no Estado de Alagoas, Brasil. Veterinária e Zootecnia, v.16, n.3, p.500-508, 2009.

QUISPE, C.H.R.; RIVERA, G.H.; ROSADIO, A.R. Cinética de la infección por Brucella ovis en carneros durante una época de empadre. Revista de Investigaciones Veterinarias del Perú, v.13, n. 1, p.61-66, 2002.

RAMOS, A.A.; MIES FILHOS, A.; SCHENCK, J.A.P.; VASCONCELLOS, L.D.; PRADO, O.T.G.; FERNANDES, J.C.T.; BLOBEL, H. Epididimite ovina, levantamento clínico no Rio Grande do Sul. Pesquisa Agropecuária Brasileira, v.1, p.211-213, 1966.

REIS, C.G. Incidência de ovinos machos reagentes a prova de imunodifusão em gel de ágar para Brucella ovis na região norte do Paraná. 2005. Trabalho de Conclusão de Curso (Graduação em Medicina Veterinária) - Universidade Norte do Paraná, Arapongas, 2005.

REVIRIEGO, F.J.; MORENO, M.A.; DOMÍNGUEZ, L. Risk factors for brucellosis seroprevalence of sheep and goat flocks in Spain. Preventive Veterinary Medicine, v.44, p. 167-173, 2000.
ROBLES, C.A. Epididimitis contagiosa de los carneros por Brucella ovis. Revista de Medicina Veterinaria, v.79, n. 1, p.67-71, 1998.

ROSENBERGER, G. Exame clínico dos Bovinos. $3^{\mathrm{a}}$ ed. Rio de Janeiro: Guanabara Koogan, 1993. 419p.

SALABERRY, S.R.S.; PAULIN, L.M.; SANTANA, R.L.; CASTRO, J.R.; LIMA-RIBEIRO, A.M.C. Pesquisa de anticorpos anti-Brucella abortus e anti-Brucella ovis em ovinos no município de Uberlândia, MG. Arquivo Brasileiro de Medicina Veterinária e Zootecnia, v.63, n.4, p.1022-1024, 2011.

SANTOS, F.A.; HIGINO, S.S.S.; AZEVEDO, S.S.; COSTA, D.F.; FARIAS, A.E.M.; ALVES F.A.L. Caracterização epidemiológica e fatores de risco associados à infecção por Brucella ovis em ovinos deslanados do semiárido paraibano. Pesquisa Veterinária Brasileira, v.33, n.4, p.459-463, 2013.

SCARCELLI, E.; PIATTI, R.M.; CARDOSO, M.V.; MIYASHIRO, S.; CAMPOS, F.R.; TEIXEIRA, S.; CASTRO, V.; GENOVEZ, M.E. Detecção de agentes bacterianos pelas técnicas de isolamento e identificação e PCR - Multiplex em fetos bovinos abortados. Revista Brasileira de Reprodução Animal, v.28, n.1, p.23-27, 2004.

SCHAFER, I.; VAZ, A.; RAMELLA, J.; COUTINHO,G. Prevalência de carneiros reagentes à prova de imunodifusão em gel para Brucella ovis no Município de Lages, SC. Hora Veterinária, v.17, v.99, p.60-61, 1997.

SILVA, J.B.A.; FEIJÓ, F.M.C.; TEIXEIRA, M.F.S.; SILVA, J.S. Prevalência de brucelose ovina causada por Brucella ovis em rebanhos do estado do Rio Grande do Norte, Brasil. Ciência Animal, v.13, n.1, p.51-54, 2003.

SILVA, N.S.; BARROS, I.N.; DASSO, M.G.; ALMEIDA, M.G.Á.R.; LABORDA, S.S.; ANUNCIAÇÃO, A.V.M.; MOREIRA, E.L.T.; LIMASILVA, A.E.; OLIVEIRA, E.M.D. Detecção de anticorpos anti-Brucella ovis em ovinos do estado da Bahia. Revista Brasileira de Saúde e Produção Animal, v. 10, n.4, p.852-859, 2009.

SOUZA, T.S.; COSTA, J.N.; MARTINEZ, P.M.; LIMA, C.C.V.; ARAÚJO, B.R.; COSTA NETO, A.O.; ANUNCIAÇÃO, A.V.M.; ALMEIDA, M.G.A.R.; PINHEIRO, R.R. Inquérito soro-epidemiológico de Brucella ovis em rebanhos ovinos no semiárido baiano. Arquivos do Instituto Biológico, v.79, n.2, p.277-281, 2012.

UENO, T. E. H. Soroprevalência de Brucella ovis em ovinos do noroeste paulista, Brasil. In: Congresso Internacional Feinco, 5, 2010, São Paulo, SP. Resumos. São Paulo: 2010.

WOLFE, D.F.; STRINGFELLOW, L.D.A.; RIDDELL, M.G.; LAUERMAN, H.; GALIK, P.K. Adherence of Brucella ovis to preimplantation ovina ova. Theriogenology, v.30, n.2, p.387-393, 1988.

WORTHINGTON, R.W.; WEDDELL, W.; PENROSE, M.E. A comparison of three serological tests for the diagnosis of Brucella ovis infection in rans. New Zealand Veterinary Journal, v.32, p.58-60, 1984. 